\title{
Multi-Objective Build Orientation Optimization for Powder Bed Fusion by Laser
}

Brika SE', Zhao YF', Brochu $\mathbf{M}^{2}$ and Mezzetta $\mathbf{J}^{2}$

${ }^{1}$ Mechanical Engineering Department, McGill University, Montreal, QC, Canada

${ }^{2}$ Mining and Materials Engineering Department, McGill University, Montreal, QC, Canada

\begin{abstract}
This paper proposes an integrated approach to determine optimal build orientation for Powder bed fusion by laser (PBF-L), by simultaneously optimizing mechanical properties, surface roughness, the amount of support structure and build time-cost. Experimental data analysis has been used to establish the objective functions for different mechanical properties and surface roughness. Geometry analysis of the part has been used to estimate the needed support structure and thus evaluate the build time and cost. Normalized weights are assigned to different objectives depending on their relative importance allowing solving the multi-objective optimization problem using a genetic optimization algorithm. A study case is presented to demonstrate the capabilities of the developed system. The major achievements of this work are the consideration of multiple objectives, the establishment of objective function considering different load direction and heat treatments. A user-friendly graphical user interface was developed allowing to control different optimization process factors and providing different visualization and evaluation tools.
\end{abstract}

Keywords: Powder bed fusion by laser; Part build orientation; Multiobjective optimization; Mechanical properties; Support structure; Build time and cost; Surface roughness; Ti-6Al-4V

Abbreviations: AM: Additive Manufacturing; PBF-L: Powder Bed Fusion by Laser; SR2: Stress Relief 2 h; A7: Annealing 704C; HIP: Hot Isostatic Pressing; Ra: Average Surface Roughness; YS: Yield Strength; UTS: Ultimate Tensile Strength; E: Elongation; HV: Vickers Hardness; $\mathrm{T}_{\text {Print }}:$ Total printing time $[\mathrm{h}] ; \mathrm{Z}_{\text {Part }}:$ Part height $[\mathrm{mm}] ; \mathrm{L}_{\text {thick }}$ : Layer thickness $[\mathrm{mm}] ; \mathrm{T}_{\text {Recoat }}$ : Recoating time $[\mathrm{h}] ; \mathrm{V}_{\text {Part }}$ : Part volume $\left[\mathrm{mm}^{3}\right] ; \mathrm{D}_{\text {Part }}$ : Part deposition rate $\left[\mathrm{mm}^{2} / \mathrm{s}\right] ; \mathrm{V}_{\text {supp }}$ : Support structure volume $\left[\mathrm{mm}^{3}\right] ; \mathrm{D}_{\text {supp }}$ : Support deposition rate $\left[\mathrm{mm}^{2} / \mathrm{s}\right] ; \mathrm{C}_{\text {Material }}$ : Total material cost $[\$] ; D_{\text {Support }}:$ Support structure concentration; $\rho:$ Material density $\left[\mathrm{kg} / \mathrm{m}^{3}\right]$; Porosity: Average material porosity; $\mathrm{P}_{\text {Material }}$ : Material price [\$/kg]; Waste: Material waste rate; $\mathrm{C}_{\text {Print }}$ : Print cost [\$]; $\mathrm{W}_{\mathrm{W}}$ Consumed material $[\mathrm{kg}] ; \mathrm{E}_{\text {cosum }}$ : Energy consumed $[\mathrm{kWh} / \mathrm{kg}] ; \mathrm{E}_{\text {Price }}$ : Energy price $[\$ / \mathrm{kWh}] ; \mathrm{C}_{\text {Indirect }}$ : Indirect cost $[\$ / \mathrm{h}] ; \mathrm{L}$ : Part length [mm]; WR: Wrought reference

\section{Introduction}

Powder bed fusion by laser (PBF-L) is one of the key Additive Manufacturing ( $\mathrm{AM}$ ) processes and one of the most widely used especially in the aerospace, automotive, and medical industries. As opposed to subtractive manufacturing where material removal occurs, the principle of PBF-L is that $3 \mathrm{D}$ parts are built by adding successive layers of fine metallic powder fused by a laser beam under computer control. Through continuous stacking of layers, net-shape components can be fabricated in a single process. This technology is capable of producing a complex object directly from the CAD model with intricate external and internal features, which are impossible to fabricate via conventional manufacturing techniques.

The PBF process starts by numerically slicing a 3D CAD model into a number of finite layers. For each sliced layer, a laser scan path is calculated. Each layer is then sequentially recreated using a high power-density laser that fully melts the pre-deposited metallic powder bed. The melted particles fuse and solidify to form the cross section shape of the component. Then a wiper uniformly spreads a new layer of powder above the melted one to create the next layer and so on until the whole part is built.
In $\mathrm{AM}$ processes and more particularly in PBF-L, the build orientation choice is one of the most influential factors on the quality, performance, and cost of the printed part. In real workshops, operators usually make that choice based on their experience and on their intuitive analysis of the part, which usually may not be the optimal build orientation choice. To deal with this problem several studies have been carried out to identify optimal orientations by considering different objectives. Singhal et al. [1] use standard optimization technique based on trust region methods to determine optimum part deposition orientation in PBF-L and selective laser sintering (SLS). They developed a multi-objective optimization approach that minimizes the weighted sum of surface roughness, build time and support structure.

Padhye and Deb $[2,3]$ applied evolutionary algorithms like multiobjective genetic algorithm (NGSA-II) and particle swarm optimizers (MOPSO) to determine the best build orientation in SLS. They used the objective function developed by Singhal et al. [1] and they just considered minimization of surface roughness and build time as objectives.

Byun and Lee [4,5] developed an algorithm to determine the optimal build orientation for different rapid prototyping processes like SLA, FDM, SLS and LOM to facilitate AM process planning. The optimal orientation is determined by three factors namely surface roughness, build time and part cost.

Mezzetta [6] studied the variation in mechanical properties and surface roughness with build orientation (anisotropy), heat treatments and printing parameters for a titanium alloy (Ti-6Al-4V) manufactured

*Corresponding author: Sleh Brika, Mechanical Engineering Department Montreal, McGill University, QC, Canada, Tel: 5143984455; E-mail: sleh.brika@mail.mcgill.ca

Received October 10, 2017; Accepted November 03, 2017; Published November 13, 2017

Citation: Brika SE, Zhao YF, Brochu M, Mezzetta J (2017) Multi-Objective Build Orientation Optimization for Powder Bed Fusion by Laser. Ind Eng Manage 6: 236. doi:10.4172/2169-0316.1000236

Copyright: ( 2017 Brika SE, et al. This is an open-access article distributed under the terms of the Creative Commons Attribution License, which permits unrestricted use, distribution, and reproduction in any medium, provided the original author and source are credited. 
by PBF-L. They established the optimal settings combination that ensures the optimal material density.

Ruffo et al. [7,8] proposed a cost estimator based on a 'full costing' concept, which included labor, material, machine absorption, production, and administrative overheads.

Baumers et al. [9] presented a combined estimator of build-time, energy consumption and production cost for the EOSINT M270 SLM system. They demonstrated that the quantity and variety of parts demanded and the resulting ability to utilize the available machine capacity impact process efficiency, both in energy and in financial terms.

However, there exists a gap in the available knowledge. Since the different approaches generally just consider two or three objectives to determine the optimum build orientation, some important factors are neglected. The build orientation generated in these ways may not generate the optimum performance and qualities of PBF parts. Hence, the importance of this work which aims to determine optimal build orientation by simultaneously optimizing mechanical properties including Yield strength, Ultimate tensile strength, Elongation, Vickers hardness, surface roughness, support structure, build time and total cost.

\section{Problem Formulation}

PBF-L produces parts with mechanical properties comparable to those of bulk materials. However, due to the "layer by layer" nature of the method, the mechanical properties of produced parts are characterized by a certain degree of anisotropy; hence, it is important to select an appropriate build orientation that considers the loading direction applied to the part. It is also possible to improve the mechanical and material properties through post-process heat treatments; however, this is time-consuming and adds to the cost.

PBF-L needs support structures to sustain overhanging surfaces to avoid build failure. Thus, a suitable build orientation can minimize the amount of overhanging surface and in turn, reduce the amount of support structure needed. The proposed approach avoids using extra material and reduces the time needed to build the support structure and remove it.

It is often desirable for an AM part to have minimized surface roughness, particularly in areas of functional importance. Bacchewar et al. [10] showed that surface roughness mainly depends on the layer thickness but also highly depends on the build orientation since the side surfaces generally present a better finish than up facing or down-facing surfaces. Surface finish can be improved through surfaces treatments; however, this is also time-consuming and adds to the cost.

The material deposition is done layer by layer along the $\mathrm{Z}$-axis of the machine, and after each layer, a new bed of powder should be spread. Therefore, the higher the part is along the $\mathrm{Z}$-axis, the more powder spreading operations will be needed and the longer is the build time and the higher is the cost.

To determine a build orientation that ensures optimal performance and quality of the AM part at the lowest cost, it is necessary to simultaneously optimize different objectives. For the current study, the objectives of interest are the average surface roughness $\mathrm{Ra}$, total build time $\mathrm{T}$, total build cost $\mathrm{C}$, average yield strength $\mathrm{YS}$, average tensile strength UTS, average elongation E, average Vickers Hardness VH and the amount of support structure SUPP. The following multi-objective optimization is set up:
Minimize $f_{1}=R a(\varphi)$
Minimize $f_{2}=T(\varphi, S U P P)$
Minimize $f_{3}=C(\varphi, T, S U P P)$
Maximize $f_{4}=Y S(\varphi, H T)$
Maximize $f_{5}=\operatorname{UTS}(\varphi, H T)$
Maximize $f_{6}=H V(\varphi, H T)$
Maximize $f_{7}=E(\varphi, H T)$
Minimize $f_{8}=\operatorname{SUPP}(\varphi)$

With $\phi=\left(\left\{\theta_{x^{\prime}} \theta_{y}\right\}\right) 0 \leq \theta_{x} \leq 360,0 \leq \theta_{y} \leq 360$ referring to the build orientation of the part.

$H T=(A 7, H I P, S R 2)$ referring to heat treatment namely annealing, hot isostatic pressing, and stress relief.

Each property is expressed in the form of an objective function according to its decision variables to be able to optimize each one. However, these objectives are interdependent and sometimes even contradictory, which makes it impossible to optimize each one separately. The solution is to bring together all the objectives functions in a main objective function, using normalized weights representing the importance and the dominance relation between the different objectives:

Optimize $f=w_{1} *{ }_{1}+w_{2} * f_{2}+\ldots+w_{n} * f_{n}$

Where $w_{i}$ is the importance weight of the objective function $f i$

However, each property has a specific unit and a different order of magnitude, the solution is to express it in a normalized way by dividing each property by its maximum value for the objectives to minimize, and dividing the minimum by the sum of the minimum and the estimated value for the objectives to maximize. In this way, the problem is represented by a main objective function to minimize, described by a weighted sum of non-dimensional values.

$$
\begin{array}{r}
\text { Minimize } f=w_{1} * \frac{f_{1}}{\operatorname{maxf_{1}}}+w_{2} * \frac{f_{2}}{\operatorname{maxf_{2}}}+w_{3} * \frac{f_{3}}{\operatorname{maxf_{3}}}+w_{4} * \frac{f_{4}}{\operatorname{maxf_{4}}}+\ldots \\
w_{5} * \frac{f_{5}}{\max _{5}}+w_{6} * \frac{f_{6}}{\operatorname{maxf}_{6}}+w_{7} * \frac{f_{7}}{\operatorname{maxf}_{7}}+w_{8} * \frac{f_{8}}{\operatorname{maxf_{8}}}
\end{array}
$$

To define the weights, industry experts were contacted and asked to rank the different objectives according to their importance and a general ranking was established by analyzing the feedbacks. Chen [11] presented an approach that converts numeric scale to fuzzy numbers using triangular membership function. Using this method, the normalized weights of the different objectives were calculated according to their importance, which is summarized in Table 1.

To solve the optimization problem, a first attempt was made using a linear programming algorithm based on the simplex method. This method needs initial guess values for $\left\{\theta_{x^{\prime}} \theta_{y}\right\}$ that represent respectively the rotation angles according to the $\mathrm{X}$-axis and $\mathrm{Y}$-axis of the machine. This method is able to converge to a global minimum but it has been noticed that the provided solution is highly dependent on the initial guess values. Furthermore, the algorithm generates a single point at each iteration which causes a lack of computation speed. A second attempt was made based on genetic algorithm (GA) method that does not need any initial guess values and generates a population of points at each iteration, which highly improves the computation time.

In this research, a genetic algorithm is used to minimize eqn. 2 and thus determine the optimum build orientation for the part. The general diagram of the optimization algorithm is shown in Figure 1. The inputs are the STL file, the load direction applied to the part and the operator requirements. The algorithm starts by randomly generate initial population values for $\left\{\theta_{x^{2}} \theta_{y}\right\}$ representing the rotation angles according to the $\mathrm{X}$-axis and $\mathrm{Y}$-axis of the machine, respectively. This solution is set as the optimal one. Then, the algorithm will try various 


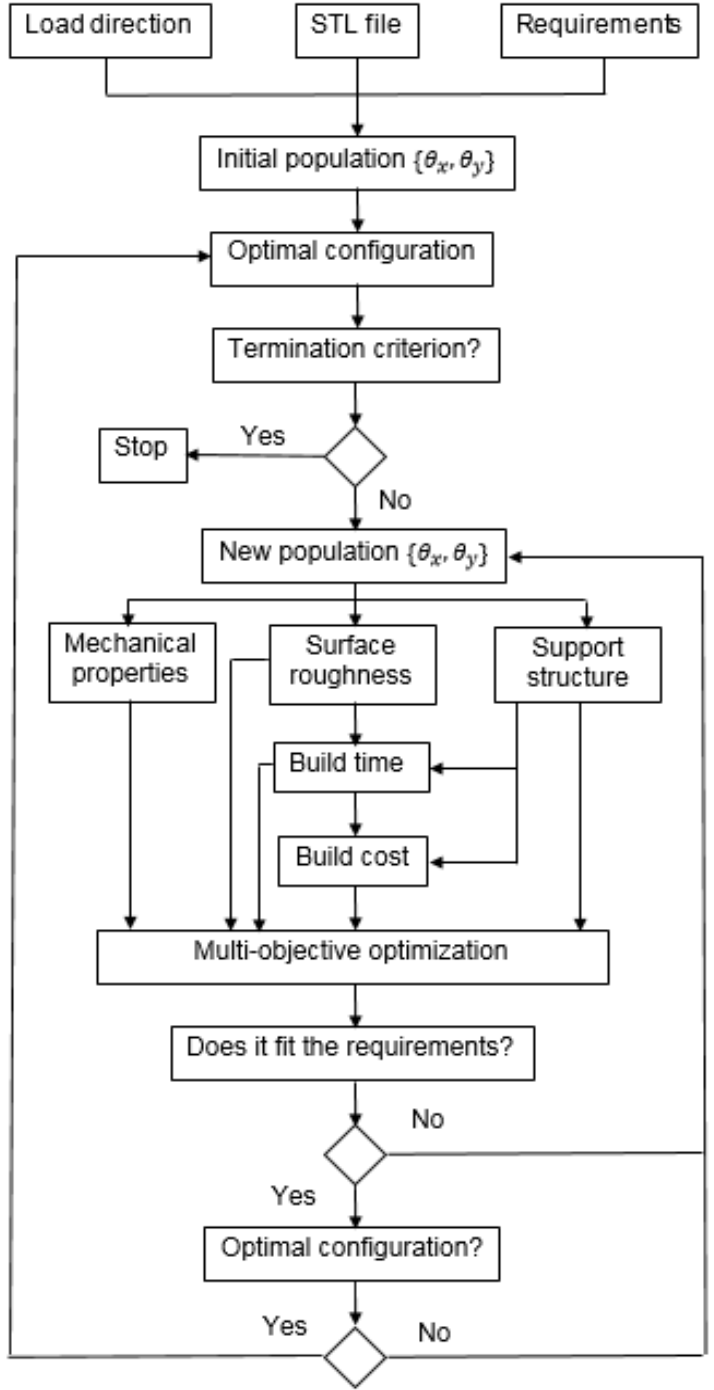

Figure 1: Optimization algorithm diagram.

solutions and for each configuration, different objective values namely mechanical properties, surface roughness, support structure build time and costs are estimated. The solution is evaluated using the eqn. 2 and the multi-objective optimization results must meet the operator requirements, and if so, the processed configuration is compared to the stored optimal configuration to determine which one is the best. This iteration continues, until obtaining the optimal build orientation of the part.

The following section describes the formulation of the different objective functions according to their decision variables.

\section{Objective Functions}

\section{Mechanical and material properties}

This work considers four mechanical properties to optimize, namely yield strength, ultimate tensile strength, elongation and Vickers hardness. Mezzetta [6] studied the behavior of those properties on Ti6Al4V parts obtained through the usage of optimal PBF machine build parameters, considering different load directions (X, 45 and Z) and different post process heat treatments (Stress relief, Mill anneal and HIP).

The obtained values of the different properties were used as a response and analysis of variance (ANOVA) was performed to understand the significance of the load direction and the heat treatment. First, full factorial method was used to establish a general equation that predicts the properties values according to the load direction and the heat treatment. A lack of accuracy was noticed on the predicted values since the established model considers simultaneously multiple heat treatments and different load directions. The model inaccuracy generates small error that could have a non-negligible impact during the optimization process. A second attempt using polynomial regression was made to establish, for each heat treatment, an equation representing the properties behavior according to the load direction, in a way that each property is described by three different equations as showed here for ultimate tensile strength.

$$
\text { SR2: }\left(43.07-0.0556^{*} \alpha-0.00102^{*}(\alpha-45)^{2}\right)^{*}(\mathrm{WR} / 100)+\mathrm{WR}
$$

$$
\begin{aligned}
& \text { A: }\left(27.4-0.0356^{*} \alpha-0.00168^{*}(\alpha-45)^{2}\right)^{*}(\mathrm{WR} / 100)+\mathrm{WR} \\
& \text { HIP: }\left(15.32-0.0378^{*} \alpha-0.00085^{*}(\alpha-45)^{2}\right)^{*}(\mathrm{WR} / 100)+\mathrm{WR}
\end{aligned}
$$

Where $\alpha \in\left[0^{\circ}, 90^{\circ}\right]$ represents the angle between the load direction and the building plate of the machine (XY plan) and WR the wrought reference of each property.

Using this method, each mechanical property (ultimate tensile strength, elongation, Vickers hardness) was defined by different equations according to heat treatments.

\section{Surface roughness}

Mezzetta [6] studied the surface roughness on Ti6Al4V samples. Different tests were performed using a constant layer thickness of $0.03 \mathrm{~mm}$ to study the roughness of up-facing and side-facing surfaces. Within this work, a model was developed based on polynomial regression linking the surface roughness with the surface orientation:

\section{$R a=9.4148+0.0389 * \theta$}

Where $\alpha \in\left[0^{\circ}, 90^{\circ}\right]$ represents the angle between the surface normal and the XY plane of the machine as shown in Figure 2.

Currently, the graphic standard for AM is the STL format, in which the surface of the $3 \mathrm{D}$ part is split into small triangles called facets. The surface roughness of each facet is calculated after estimating the normal of each triangle using the right-hand rule and evaluating the angle $\theta$ with the vertical axis of the machine using the given equation:

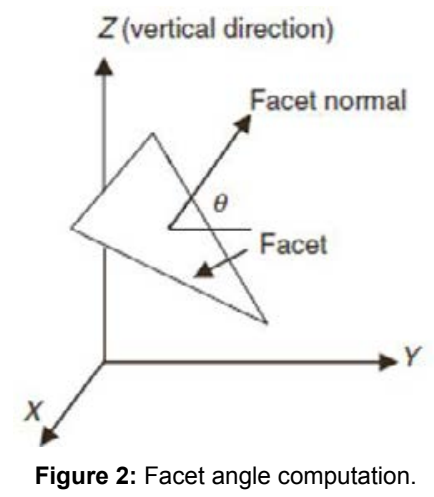




$$
\theta=\arcsin \frac{\left|A \cdot u_{1}+B \cdot u_{2}+C \cdot u_{3}\right|}{\sqrt{A^{2}+B^{2}+C^{2}} \cdot \sqrt{u_{1}^{2}+u_{2}^{2}+u_{3}^{2}}}
$$

Where $\vec{n}=(A, B, C)$ the facet normal and $\vec{u}=\left(u_{1}, u_{2}, u_{3}\right)$ the vertical axis.

The average surface roughness of the part can be calculated by

$$
R a_{a v}=\frac{\sum R a_{i} A_{i}}{\sum A_{i}}
$$

Where $R a_{i}$ and $A_{i}$ are surface roughness and area of $\mathrm{i}^{\text {th }}$ triangular facet, respectively.

\section{Support structure}

The support structure is needed to avoid the collapsing of the part and avoid the build failure by sustaining overhanging surfaces and thin features. In PBF-L process, in the conditions studied, overhangs with an angle greater than 40 degrees, as shown in Figure 3, can be built without requiring a support structure [12].

Support structures pose many problems: extra time, material and cost; the access is often limited, which makes removal difficult and it also leaves marks on surfaces which can be incompatible with finishing requirements. To avoid those disadvantages, the support structures should be minimized by choosing a suitable build orientation.

For this, the facets orientations are evaluated using eqn. 5 and the overhangs Orientation $\left[0^{\circ} 30^{\circ}\right]$ ) are detected. Then the overhanging facets are extruded until intersecting the build plate or another region of the part. To determine the extrusion offset, the Moller Trombone ray-triangle intersection algorithm is used. The ray is defined by a line starting from the center of the overhanging facet, that extends perpendicularly to the build plate and the intersection points with the facets bellow the ray origin are evaluated. The point with the higher value according to Z-axis is defined as the limit of the extrusion offset.

\section{Build time and cost}

Time and cost estimation is a critical requirement given the high costs of PBF-L process especially due to the use of high- quality titanium alloy powder, high-performance machinery, skilled labor and expensive post-processing operations.

Baumers et al. [9] established a generic model for build time and cost estimation for AM processes. By adapting the proposed model to PBF-L process specifications, a new model was developed in this research.

The printing time print depends on machine parameters namely laser spot size, laser scan speed, hatch spacing, layer thickness; powder spreading time; volume, total surface and height of the part; and the amount of support structure. The printing time was modeled as:

$$
T_{\text {Print }}=\frac{\mathrm{Z}_{\text {part }}}{\mathrm{L}_{\text {thick }}} * \mathrm{~T} \text { Re coat }+\left(\frac{\mathrm{V}_{\text {part }}}{\mathrm{L}_{\text {thick }}} * \mathrm{D}_{\text {part }}\right)+\left(\frac{\mathrm{V}_{\text {sup } \mathrm{p}}}{\mathrm{L}_{\text {thick }}} * \mathrm{D}_{\text {sup }}\right)
$$

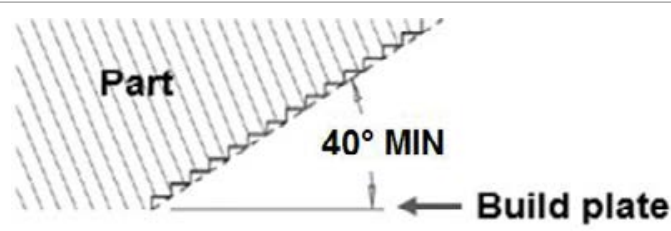

Figure 3: Minimum angle of overhangs
The deposition rate is estimated as:

$D_{\text {rate }}=$ Scan speed $*\left(\right.$ Laser spot diameter $\left.-\frac{\text { Hatch spacing }}{2}\right)$

The build cost is defined by the material and the printing cost:

$C_{\text {Tot }}=C_{\text {Material }}+C_{\text {Print }}$

The material cost represents the price of the total amount of used powder including the material needed for printing the part and the support structure as well as the amount of wasted material during the print. The material cost $C_{\text {Material }}$ can be expressed as:

$$
C_{\text {material }}=\left(V_{\text {part }}+\frac{V_{\text {support }}}{D_{\text {support }}}\right) * \rho * \text { Porosity } * P_{\text {material }} *(1+\text { Waste })
$$

The printing cost $\mathrm{C}_{\mathrm{print}}$ represents the total price of the printing operation including the consumed energy cost and the indirect cost. Baumers et al. [9] reported the energy consumption results for different selective laser melting machines and expressed the energy consumption rate per weight unit $[\mathrm{MJ} / \mathrm{kg}]$ for each machine. Furthermore, Ruffo et al. [7] established a detailed costing model including direct and indirect cost rate per hour $[\$ / h]$ of the EOSINT M270 machine considering machine cost and utilization rate; and by estimating production, labor and administrative overheads. All data used in the costing model are summarized in Table 2.

The printing cost $\mathrm{C}_{\text {Print }}$ can be expressed as:

$$
\mathrm{C}_{\text {Print }}=W_{\text {Material }} * E_{\text {cosum }} * E_{\text {Price }}+T_{\text {Print }} * C_{\text {Indirect }} * \frac{L * W}{A_{\text {Plate }}}
$$

Since the used data for indirect cost and energy consumption were established based on a full build plate, the proposed model $\frac{L * W}{A_{\text {Plate }}}$ uses to estimate the portion of the build plate used by the part in order to estimate the print cost for a single part.

\section{Case Study}

The following section presents a study case of a Ti-6Al-4V part

\begin{tabular}{|c|c|c|}
\hline Rank & Objective & Weight \\
\hline 1 & Yield strength & 0.2509 \\
\hline 2 & Tensile strength & 0.2191 \\
\hline 3 & Build cost & 0.1873 \\
\hline 4 & Surface roughness & 0.1405 \\
\hline 5 & Elongation & 0.0936 \\
\hline 6 & Build time & 0.0621 \\
\hline 7 & Support structure & 0.0306 \\
\hline 8 & Vickers Hardness & 0.0159 \\
\hline
\end{tabular}

Table 1: Objectives normalized weight.

\begin{tabular}{|c|c|c|}
\hline Variable & Value & \multirow{2}{*}{ Source } \\
\hline Layer thickness & $0.03 \mathrm{~mm}$ & \multirow{2}{*}{ Mezzetta et al. [6] } \\
\hline Scan speed & $1250 \mathrm{~mm} / \mathrm{s}$ & \\
\hline Laser spot size & $20 \mu \mathrm{m}$ & \multirow{2}{*}{} \\
\hline Hatch spacing & $0.07 \mathrm{~mm}$ & \\
\hline Density & $4.43 \mathrm{~g} / \mathrm{mm}^{3}$ & \\
\hline Porosity & $99.5 \%$ & \multirow{2}{*}{ Machine datasheet } \\
\hline Recoating time & $20 \mathrm{~s}$ & Supplier's website \\
\hline Material cost & $300 \$ / \mathrm{kg}$ & Hydro Quebec \\
\hline Energy cost & $0.18 \$ / \mathrm{kWh}$ & Ruffo [7] \\
\hline Indirect cost & $53.35 \$ / \mathrm{h}$ & Baumers [9] \\
\hline Energy consumption & $162.13 \mathrm{kWh} / \mathrm{kg}$ & \\
\hline
\end{tabular}

Table 2: Data used for build cost and time model. 
(Figures 4 and 5). Mechanical properties, surface roughness, support structure, time and build cost evaluation of three different build orientations are presented.

A mechanical properties evaluation module was developed under MATLAB, which can accurately estimate the part performance for different build orientations as shown in Figure 6 using eqn. 3 considering the applied load direction. Table 3 presents the results in terms of (\%) relative to wrought reference (WR+x \%).

A surface roughness evaluation module was developed allowing determining the surface finish of each surface and evaluating the average roughness of the part for different build orientation using eqns. 4 and 5. Figure 7 and Table 4 show the results of the developed module to evaluate surface roughness of a part according to different build orientations.

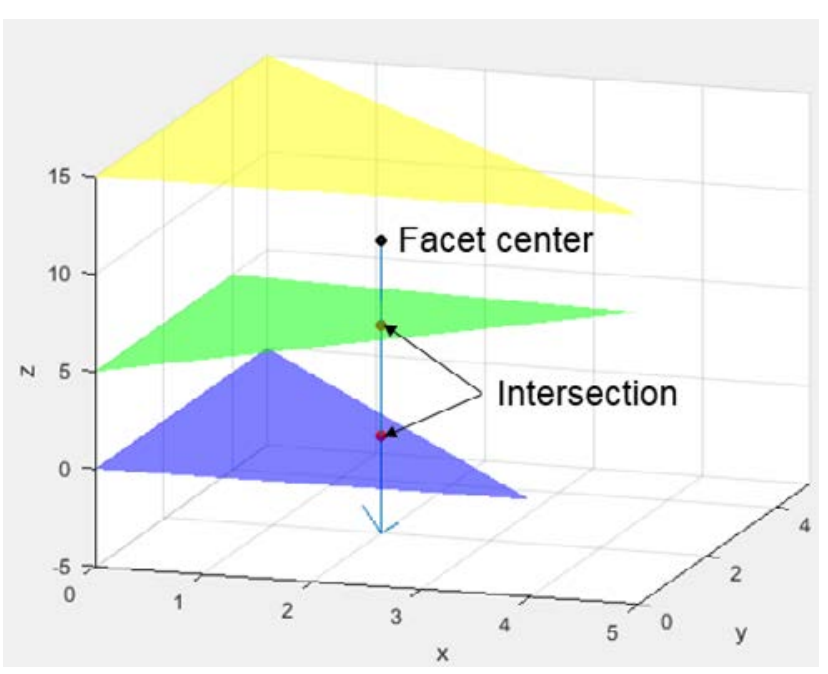

Figure 4: Extrusion offset algorithm.

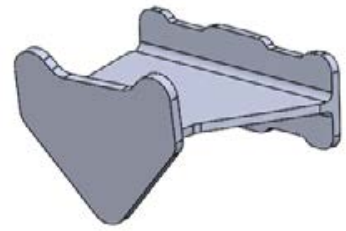

Volume : $22896,86 \mathrm{~mm}^{3}$

Area : $\quad 15927,11 \mathrm{~mm}^{2}$

Weight: $101,41 \mathrm{~g}$

L*W*H: $\quad 65,85^{\star} 77,89^{\star} 51,46 \mathrm{~mm}$

Figure 5: Case study of a Ti-6Al-4V part
A module was developed to detect the overhanging surfaces and generate the needed support with estimating the total volume and the total contact area. Figure 8 and Table 5 show the result of the developed module.

Table 6 shows the result of the developed module to evaluate the build time and cost of a part according to different build orientations as shown in Figure 8.

\section{Graphical User Interface}

A graphical user interface was developed using MATLAB allowing the user to load the CAD model, define the load direction and set the different part requirement as presented in Figures 9 and 10. The user has also the possibility to control the importance weights values and thus customize the optimization process.

After setting the load direction and defining the different requirements, the optimization process will run until finding the optimal configuration and present the optimization results with the different properties values and various visualization tools allowing the user to evaluate the proposed configuration as shown in Figure 11.

Another module (Figure 12) had also been developed allowing the user to evaluate the different objectives for any build orientation according to any load direction without the need to run the optimization process, which could, sometimes, require a long processing time. Different visualization tools are available for the user, to promptly

\begin{tabular}{|c|c|c|c|}
\hline Orientation & {$\left[92^{\circ}, 0^{\circ}, 0^{\circ}\right]$} & {$\left[180^{\circ}, 20^{\circ}, 0^{\circ}\right]$} & {$\left[25^{\circ}, 30^{\circ}, 20^{\circ}\right]$} \\
\hline \multicolumn{4}{|c|}{ Yield strength } \\
\hline Stress relief & $+37,28 \%$ & $+45,22 \%$ & $+44,89 \%$ \\
\hline Anneal & $+20,87 \%$ & $+26,08 \%$ & $+28,58 \%$ \\
\hline HIP & $+8,80 \%$ & $+12,83 \%$ & $+15,11 \%$ \\
\hline \multicolumn{4}{|c|}{ Ultimate tensile strength } \\
\hline Stress relief & $+41 \%$ & $+41,3 \%$ & $+41,2 \%$ \\
\hline Anneal & $+24 \%$ & $+25,6 \%$ & $+26 \%$ \\
\hline HIP & $+13,6 \%$ & $+14 \%$ & $+14,2 \%$ \\
\hline \multicolumn{4}{|c|}{ Elongation } \\
\hline Stress relief & $-77,14 \%$ & $-74,28 \%$ & $-74,28 \%$ \\
\hline Anneal & $-46,43 \%$ & $-40 \%$ & $-38,57 \%$ \\
\hline HIP & $-12,85 \%$ & $+3,57 \%$ & $+10 \%$ \\
\hline \multicolumn{4}{|c|}{ Vickers hardness } \\
\hline Stress relief & $+7,18 \%$ & $+6,15 \%$ & $+6,15 \%$ \\
\hline Anneal & $+1,28 \%$ & $+1 \%$ & $-0,26 \%$ \\
\hline HIP & $-4,10 \%$ & $-4,62 \%$ & $-4,66 \%$ \\
\hline
\end{tabular}

Table 3: Mechanical properties results.

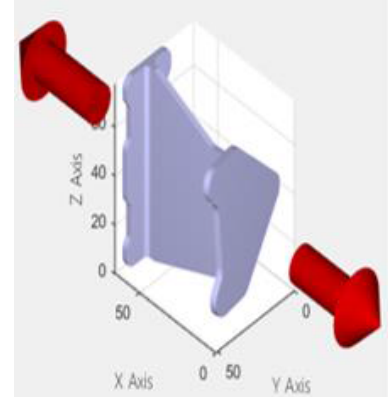

Orientation 1

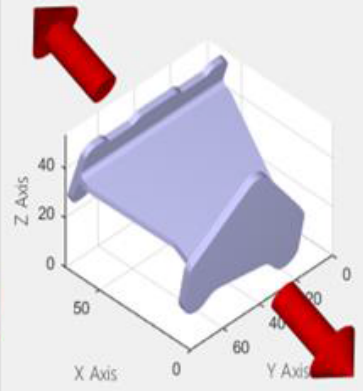

Orientation 2

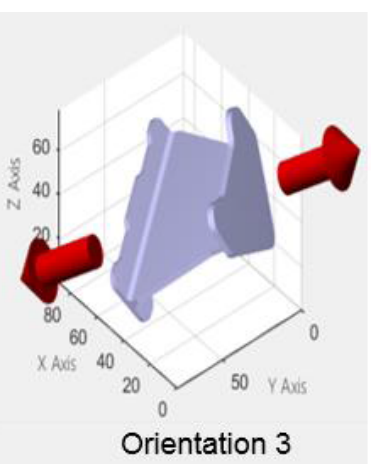

Figure 6: Load direction according to different build orientations. 


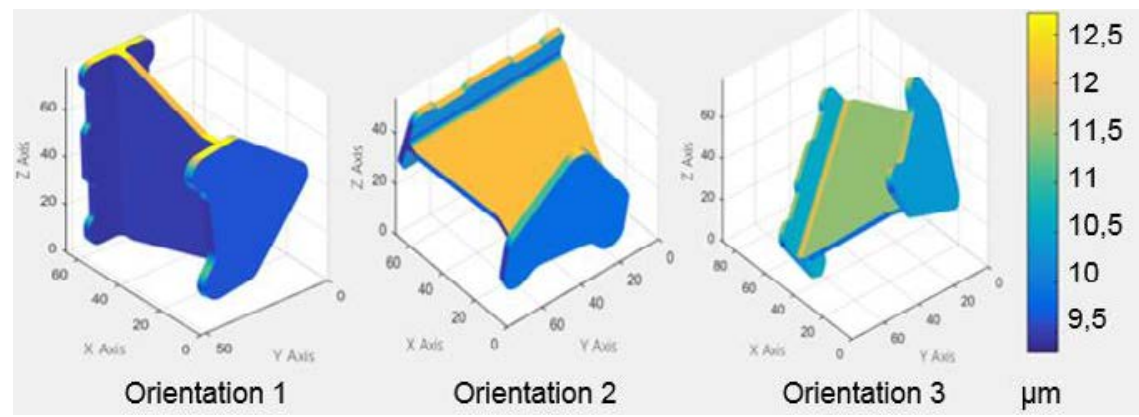

Figure 7: Surface roughness evaluation.
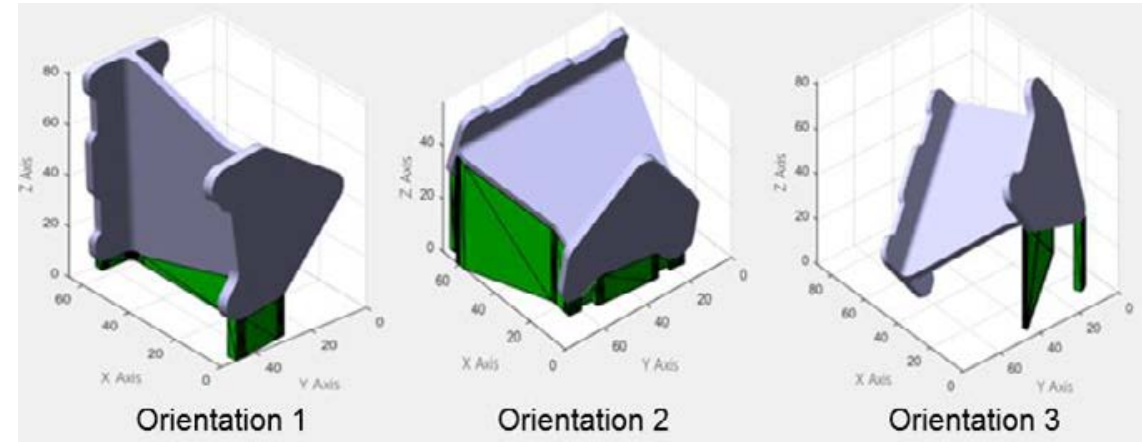

Figure 8: Support structure generation.

\begin{tabular}{|c|c|c|}
\hline Orientation & {$[\mathbf{R x}, \mathbf{R y}, \mathbf{R z}]$} & Average roughness $(\boldsymbol{\mu m})$ \\
\hline Orientation 1 & {$\left[92^{\circ}, 0^{\circ}, 0^{\circ}\right]$} & 9.675 \\
\hline Orientation 2 & {$\left[180^{\circ}, 20^{\circ}, 0^{\circ}\right]$} & 11.014 \\
\hline Orientation 3 & {$\left[25^{\circ}, 30^{\circ}, 20^{\circ}\right]$} & 10.924 \\
\hline
\end{tabular}

Table 4: Average surface roughness.

\begin{tabular}{|c|c|c|c|}
\hline Orientation & Contact $\mathbf{~ m m}^{\mathbf{2}}$ & Volume $\mathbf{m m}^{\mathbf{3}}$ & BTF \\
\hline$\left[92^{\circ}, 0^{\circ}, 0^{\circ}\right]$ & 307.22 & 3065 & 1.228 \\
\hline$\left[180^{\circ}, 20^{\circ}, 0^{\circ}\right]$ & 3644.23 & 115656 & 6.051 \\
\hline$\left[25^{\circ}, 30^{\circ}, 20^{\circ}\right]$ & 124.41 & 6353 & 1.315 \\
\hline
\end{tabular}

Table 5: Support structure results for different build orientations.

\begin{tabular}{|c|c|c|c|}
\hline Orientation & $\mathbf{1}$ & $\mathbf{2}$ & $\mathbf{3}$ \\
\hline Material used $(\mathrm{kg})$ & 0.113 & 0.5947 & 0.1284 \\
\hline Material for support $(\mathrm{kg})$ & 0.012 & 0.493 & 0.0274 \\
\hline Material cost $(\mathbf{})$ & 34.266 & 180.183 & 38.9 \\
\hline Time for support $(\mathrm{h})$ & 15.055 & 30.754 & 15.776 \\
\hline Total exposure time $(\mathrm{h})$ & 8.992 & 29.224 & 9.634 \\
\hline Total recoating time $(\mathrm{h})$ & 14.544 & 10.011 & 14.622 \\
\hline Consumed energy $(\mathrm{KWh})$ & 17.35 & 56.39 & 18.58 \\
\hline Energy cost $(\$)$ & 3.32 & 17.354 & 3.346 \\
\hline Indirect cost $(\$)$ & 78.915 & 199.801 & 158.389 \\
\hline Build time $(\mathrm{h})$ & 23.536 & 39.235 & 24.256 \\
\hline Build cost $(\$)$ & 116.481 & 397.339 & 201.035 \\
\hline
\end{tabular}

Table 6: Build time and cost.

evaluate and compare different configurations. The proposed module is completely customizable due to the different setting panels allowing varying the importance weights, heat treatments, visualization scales and time and costing variables.

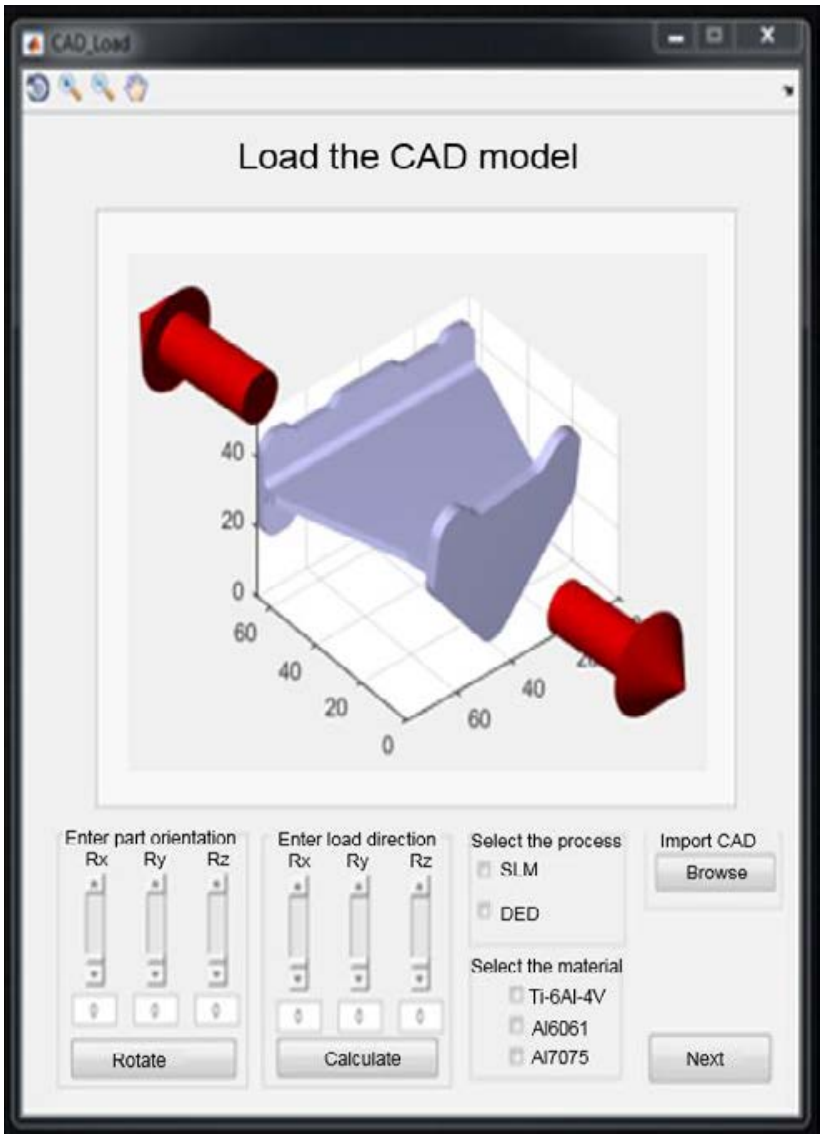

Figure 9: Graphical user interface. 
Citation: Brika SE, Zhao YF, Brochu M, Mezzetta J (2017) Multi-Objective Build Orientation Optimization for Powder Bed Fusion by Laser. Ind Eng Manage 6: 236. doi:10.4172/2169-0316.1000236

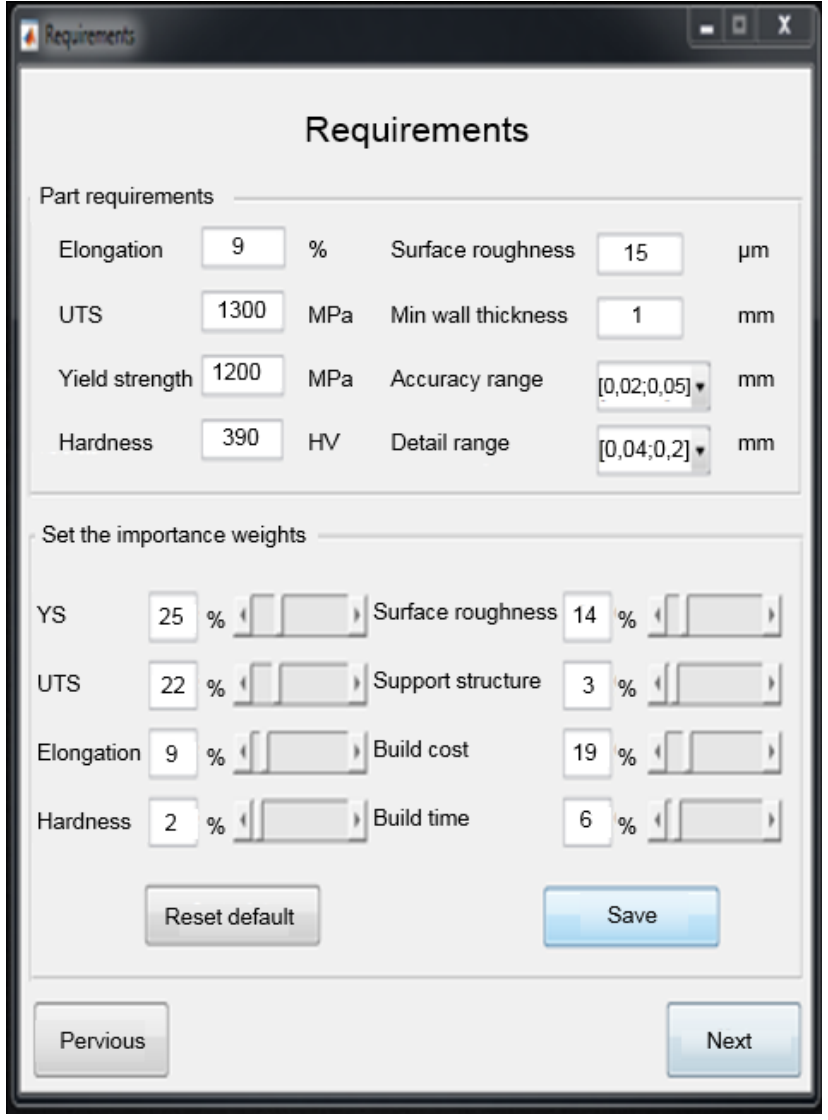

Figure 10: Requirements frame.

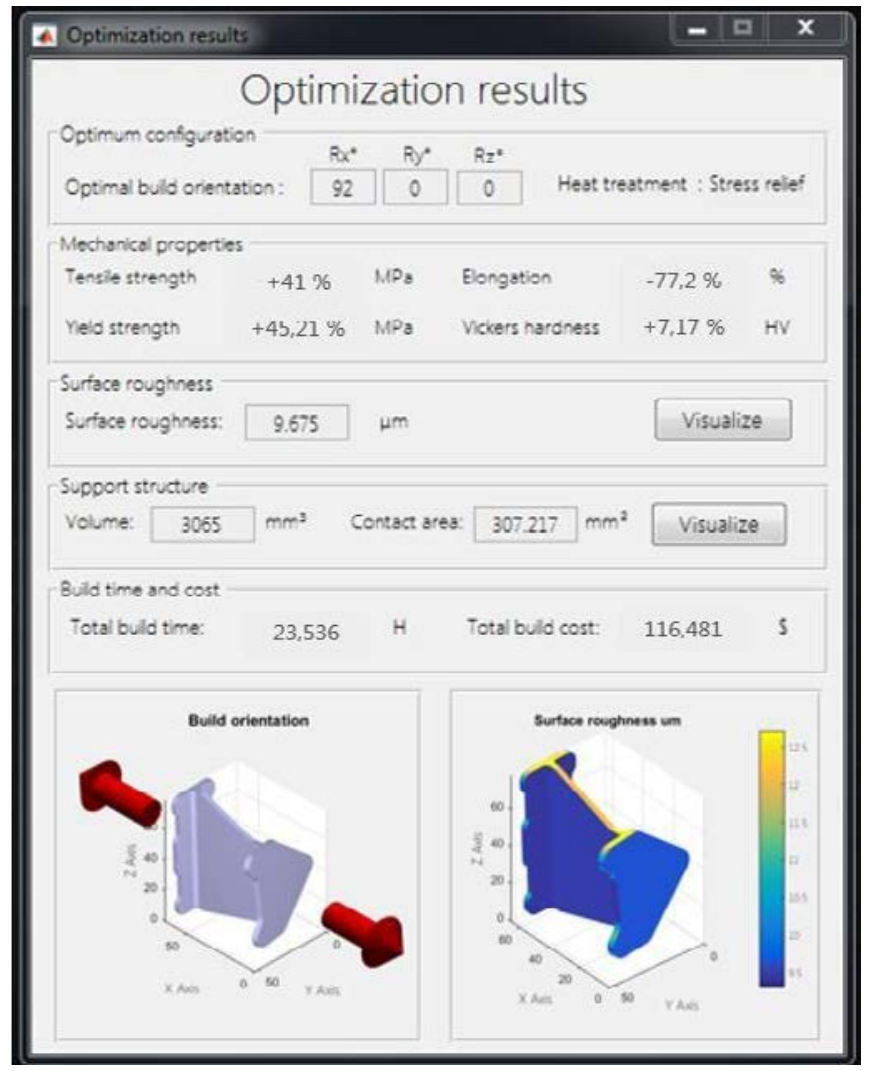

Figure 11: Optimization results frame.

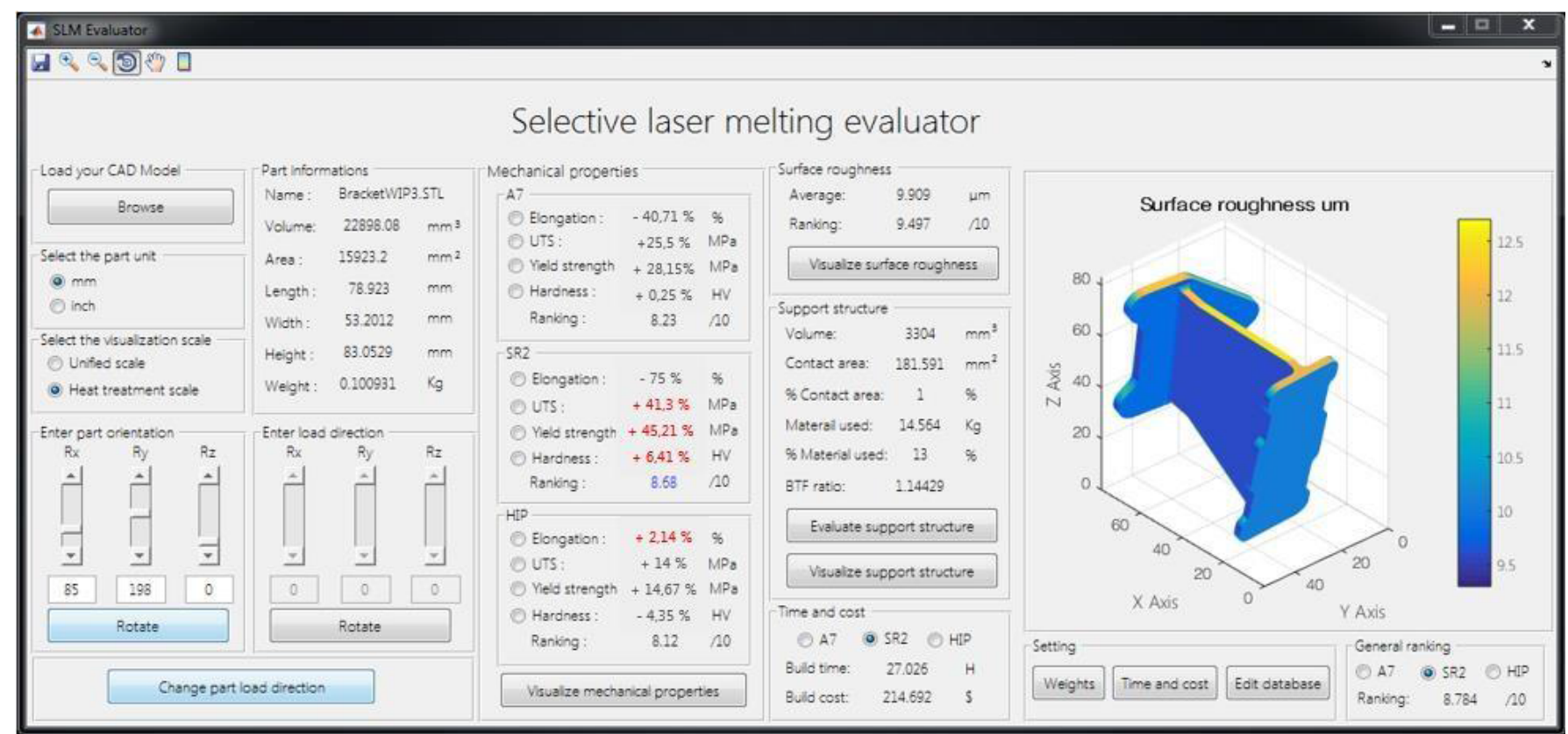

Figure 12: Selective laser melting evaluator.

\section{Optimization Results}

Figures 13 and 14, Tables 7 and 8 show the optimization results generated by the developed model for different parts built with Ti-6Al-
$4 \mathrm{~V}$ with the estimated values for the different mechanical properties (in terms of $\%$ relative to wrought reference), surface roughness and build time and cost. 


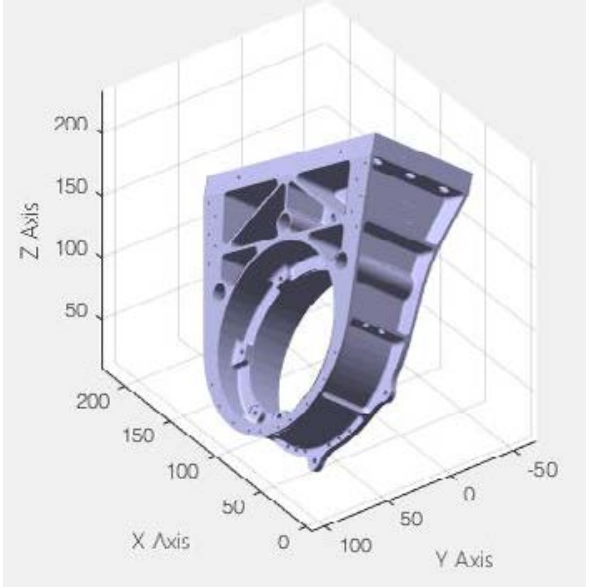

Figure 13: Optimum builds orientation part 1.

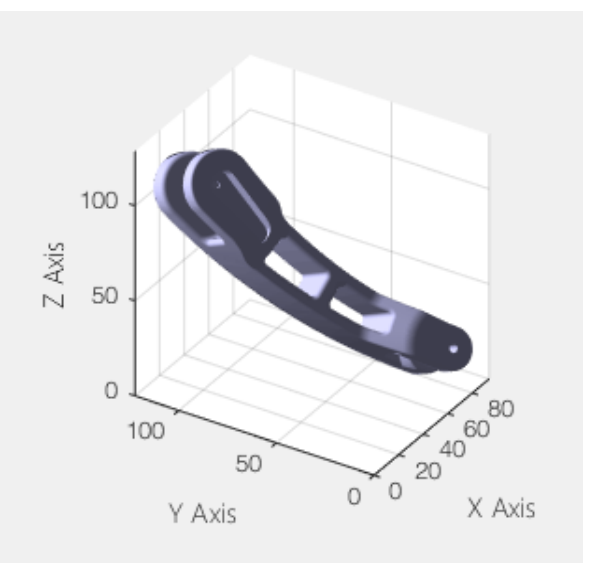

Figure 14: Optimum builds orientation part 2.

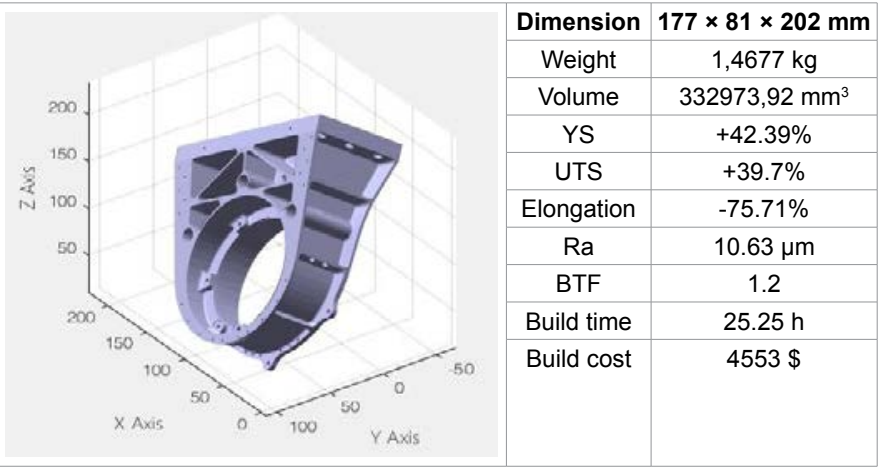

Table 7: Optimization results part 1

\section{Discussion}

The program accuracy mainly depends on the developed objective functions veracity established by statistical analysis of experimental data. The bigger the database the more accurate are the objective function and thus the program results.

The processing time of the optimization algorithm highly depends on the part geometry complexity and the number of elements in the mesh. The support structure evaluation module is the most time consuming since it has to detect the overhangs surfaces and then

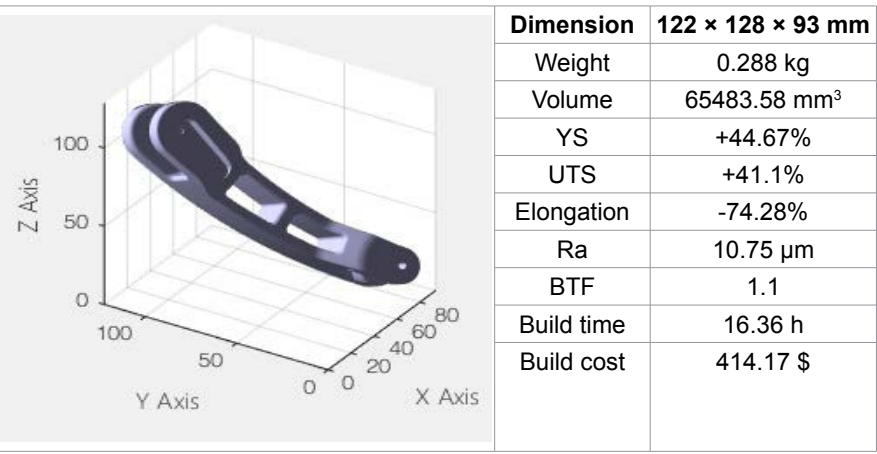

Table 8: Optimization results part 2.

generate the support structure considering the intersection with the part and the build plate. The current optimization algorithm is using genetic algorithm method; processing time could be improved by using an evolutionary optimization algorithm as the non-dominated sorting genetic algorithm NSGA-II as described by Padhye and Deb [2].

A small meshing provides more accurate results but it highly increases the number of operations, and a too large meshing can skew the evaluation results. Therefore, a suitable mesh size has to be chosen when preparing the STL file.

The proposed time and cost module factors values are collected from different sources due to the lack of a unique detailed time and cost documentation, which leads to a rough approximation of the build time and cost.

\section{Conclusion}

In this research, software has been developed to automatically determine the optimum build orientation for selective laser melting by simultaneously optimizing different objective namely surface roughness, yield strength, ultimate tensile strength, elongation, Vickers hardness, support structure amount and build time and cost. First, mechanical properties and surface roughness objective functions were established by statistically analyzing the experimental data; the remaining properties were evaluated by analyzing the part geometry and using different developed model. A multi-objective was adopted to simultaneously optimize the different objective using normalized importance weights.

This research provides a useful tool for the user to decide the build orientation of a part for selective laser melting according to a given load direction and different requirements. The proposed software provides also different visualization and evaluation tools and offers a great freedom to the user since almost all the optimization factors are customizable.

\section{Acknowledgment}

The author is grateful to the "Consortium de recherche et innovation en aéronautique du Québec" (CRIAQ), McGill University and the École Polytechnique de Montréal, as well as Bell Helicopter Textron Canada, Bombardier, Edmit, GE Aviation, Héroux- Devtek, Liburdi, MDA and Pratt Whitney Canada for their collaboration and involvement in the MANU601 project.

\section{References}

1. Singhal SK, Jain KP, Pandey MP, Nagpal AK (2009) Optimum part deposition orientation for multiple objectives in SL and SLS prototyping. International Journal of Production Research 47: 6375-6396.

2. Padhye N, Deb K (2011) Multi-objective optimization and multi-criteria decision making in SLS using evolutionary approaches. Rapid Prototyping Journal 17: 458-478. 
Citation: Brika SE, Zhao YF, Brochu M, Mezzetta J (2017) Multi-Objective Build Orientation Optimization for Powder Bed Fusion by Laser. Ind Eng Manage 6: 236. doi:10.4172/2169-0316.1000236

Page 9 of 9

3. Pandey PM, Thrimurtullu K, Reddy NV (2004) Optimal part deposition orientation in FDM by using a multi- criteria genetic algorithm. Internationa Journal of Production Research 42: 4069-4089.

4. Byun HK, Lee KH (2006) Determination of the optimal build direction for different rapid prototyping processes using multi-criterion decision making. Robotics and Computer-Integrated Manufacturing 22 Journal.

5. Byun HS, Lee KH (2005) Determination of the optimal part orientation in layered manufacturing using a genetic algorithm. International Journal of Production Research 43: 2709-2724

6. Mezzetta J (2016) Process-property relationships of Ti6Al4V fabricated through selective laser melting. McGill University.

7. Ruffo M, Tuck C, Hague R (2006b) Cost estimation for rapid manufacturing laser-sintering production for low to medium volumes. Proceedings of IMechE Part B: Journal of Engineering Manufacture 220:1417-1427.
8. Ruffo M, Tuck C, Hague R (2006a) Empirical laser sintering time estimator for Duraform PA. International Journal of Production Research 44: 5131-5146.

9. Baumers M, Tuck C, Wildman R, Ashcroft I, Rosamond E, et al. (2013) Combined build-time, energy consumption and cost estimation for direct metal laser sintering.

10. Bacchewar PB, Singhal SK, Pandey PM (2007) Statistical modeling and optimization of surface roughness in selective laser sintering process. Proceedings of the IMechE Journal of Engineering Manufacture 221: 35-52.

11. Chen SM (1997) A new method for tool steel materials selection under fuzzy environment. Fuzzy Sets and Systems 92.3: 265-274.

12. Jarvinen JP, Ville-Pekka M, Xiaoyun L, Heidi P, Antti S, et al. (2014) Characterization of effect of support structures in laser additive manufacturing of stainless steel. Physics Procedia 56: 72-81. 